\title{
An Examination to Advance / Develop Organization Citizenship Behavior
}

\author{
J. M. Jaffar Sadiq
}

\begin{abstract}
It is viewed as the marvel of Organization citizenship conduct from when the idea showed up in the writing as of recently, its definition and evolving nature. Likewise, it has broke down the connection among organization citizenship behavior and interrelated concepts, its organization with Organization culture, demeanors, ethics, and so on. The motivation behind this Investigation disclose how to advance Organization citizenship behavior, conduct and to build up an arrangement to get ceaseless organization citizenship behavior through prescribed framework and casual ecological setting in work place. Organization citizenship behaviors (organization citizenship behavior) portray activities in which workers are happy to go well beyond their recommended job prerequisites. A few examinations have demonstrated that organization citizenship behavior are emphatically identified with pointers of individual, unit, and Organization execution. This Investigation centers around unmistakably characterizing the connection between Organization adequacy and Model of organization citizenship behavior. It will likewise talk about the ramifications of the organization citizenship behavior and attempt to discover how to advance organization citizenship behavior. Outcomes demonstrate that constructive work atmosphere, organization assets, representative's character, Organization culture, etc are altogether identified with organization citizenship behavior. This exploration is significant for any organizations which need to make capability and Organization viability. To advance organization citizenship behavior is most reduced expense and most ideal route for organizations to arrive at Organization adequacy.
\end{abstract}

Keywords : : Organization culture, demeanors, ethics, Motivation, organization citizenship behavior, Organizations, Organization adequacy, Execution.

\section{INTRODUCTION}

$\mathrm{O}_{\text {ne fascinating theme that rose in the writing over two }}$ decades prior is about representative's inspiration to participate in undertaking execution. It infers not exclusively to the fundamental errand necessities yet in addition to the next non-prescribed undertaking prerequisites. Numerous creators don't concur on general conclusion about employment necessities. They state that activity prerequisites are the one that are officially composed as well as incorporate other non-composed necessities. It's own selection of workers whether they need to take part in extra, non-prescribed

Revised Manuscript Received on December 05, 2019.

* Correspondence Author

J. M. Jaffar Sadiq*, Assistant Professor, Department of Commerce, The New College (Autonomous), Chennai, Tamil Nadu, India. Email Jaffar_Sadiq3@yahoo.com prerequisites. Organization behavior as a control is attempting to clarify human conduct, purposes behind various sorts of conduct, its points of interest and drawbacks. The objective is to increment Organization viability and productivity utilizing the most significant creation which is human factor. Organization philosophy in definite manner characterizes representative's conduct, frames of mind and qualities. Making sufficient organization culture where achievement, cooperation, imagination, steadfastness, correspondence and different qualities are significant is a most of the way to the organization achievement. Every representative ought to be keen on accomplishing Organization objectives since it helps in accomplishing individual objectives which results in generally speaking fulfillment.

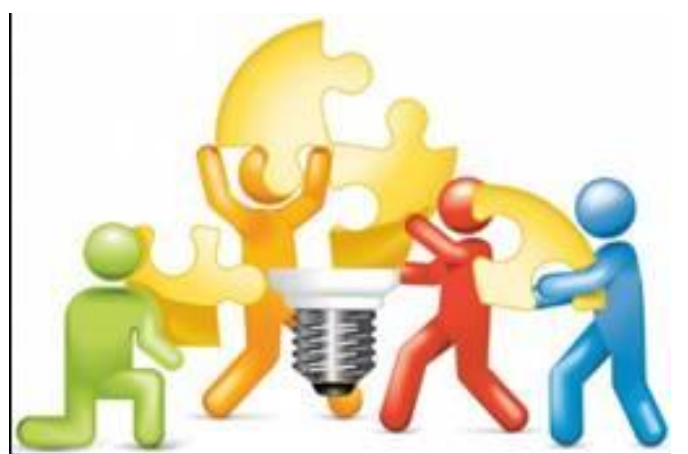

The world is anticipating superior organizations, which would give high work fulfillment to their representatives and would likewise treasure brilliance and adequacy. This could be accomplished on the off chance that we could create Organization citizenship.

\section{OBJECTIVES OF THE STUDY}

- To identify and develop the Organization citizenship behavior and the process of attainment

- To explicate the plan and strategy in order to obtain persistent organization citizenship behavior through recognized \& prescribed system and proper conservational system in workplace

- To outline the bond among Organization efficiency and organization citizenship behavior

- To Highlight the Inferences of organization citizenship behavior, figure out the purpose and necessary ways to develop and advance organization citizenship behavior 


\section{TEST OF HYPOTHESIS}

- There is no result of organization Citizenship behavior among workers in the organization.

- There is a result of organization Citizenship behavior among workers in the organization.

- There is the same strategy pursued by the Employees under Organization Citizenship behavior which is under developing phase.

- There is an alternate strategy utilized by the employees under Organization Citizenship behavior which is not under developing phase.

\section{RESEARCH METHODOLOGY}

This investigation depends on essential information just as auxiliary information. Sources of information regarding organizational Citizenship behavior among employees gathered from the Reviews. In this Research the secondary data has been analyzed through articles, Reviews From author and internet information as needed.

\section{LITERATURE OF REVIEW}

Organizational citizenship behavior (Organization Citizenship behavior) as an idea is presently right around 25 years of age. In any case, in the current hypercompetitive business condition, where organizations are searching for anything which can support them accomplish upper hand, organization citizenship behavior may well give the appropriate response. The starting point of this idea can be followed to the principal writer of this article, who distributed a paper titled 'A Reappraisal and Reinterpretation of the Fulfillment Causes-Execution Theory's in 1977. The paper took a gander at the easygoing and inconspicuous commitments of workers, which can't be caught by quantitative hard proportions of yield. The term organization citizenship behavior was first utilized by Dennis W. Organ in quite a while thinks about in 1983 with two of his doctoral understudies, (Tom Bateman and C Ann Smith).

It is amazingly significant for two reasons. Aside from being composed by Dennis Organ, the pioneer of the idea of organization citizenship behavior, the article comes when the idea has voyage just about 25 years. The target is to return to the achievements over the span of its adventure, clear a portion of the ambiguities which have been made and distinguish and address the holes that have created during this period. It takes a relook at changed connections and makes some new ones, which will give its per users some important and fascinating bits of knowledge into the idea of organization citizenship behavior. The total and impartial perspective on the historical backdrop of the idea that develops is estimable, taking into account that one of the creators made the idea.

Section 1 uses the demonstrations and intentions of a representative named 'Sam' to depict the complexities of the term organization citizenship behavior. The examination of what Sam does, why he does it, and how he does it enables per users to perceive the different issues engaged with

organization citizenship behavior and its significance in the organization setting. It enables per users to isolate this idea from philanthropy. Section 2 gives a rich perspective on the authentic start of this idea. It gives a depiction of the different sorts of organization citizenship behavior, its social variations and a look into points like relevant execution, pro-social organization behavior, extra-job behavior and issues relating to build legitimacy of organization citizenship behavior measures. Section 3 places this idea close by different ideas of organization hypothesis including casual organization, trade and power, various commitments by organizational members, execution examination, LMX, and exchange cost financial aspects (Dennis W Organ, Philip M Podsakoff \& Sco).

Section 2 takes a gander at the forerunners of organization citizenship behavior, for example, attitudinal, dispositional, character, workplace and authority and the exploration that has been done into these precursors. It takes a gander at the basic separation between workers, task routine, task formalization, character qualities, confidence and so forth Section 3 takes a gander at the effect of organization citizenship behavior how organization citizenship behavior will influence administrative assessments, administrative choices, execution measures, impression the board, compensate assignment and organization proficiency. It additionally harps on what it implies for HR experts regarding distinctive HR capacities like enlistment and choice, pay, preparing and advancement, and execution estimation (Dennis W Organ, Philip M Podsakoff \& Sco).

Dennis W Organ $\{1988\}$ recommended that abnormal amounts of organization citizenship behavior should prompt an increasingly effective association and aid carrying new assets into the organization. In W. Dennis Organ's clarification, verifying required assets alludes not exclusively to the fascination of new individuals or crude materials, yet in addition to such immaterial factors as organization positive attitude, or the outer picture and notoriety of the organization. In this way, client impression in the association or administrations becomes outer appraisal in terms of adequacy which is impacted by organization citizenship behavior.

The Current examination analyzed connections among organization citizenship behavior and Organization viability. A couple of studies have demonstrated that organization citizenship behavior are decidedly identified with markers of individual, unit, and Organization execution. Organization citizenship behavior are presumably possessing Multiple decisions . There is no solitary reason for organization citizenship behavior. Hypothetical systems for every single different class of Organization conduct, from occupation execution to turnover to non-attendance, incorporate numerous wellsprings of causation. It bodes well to apply a similar method of 
reasoning to organization citizenship behavior. Unwinding the "Solitary reason" parameter will keep the quest for elements of organization citizenship behavior from getting to be limited in center and exclusionary in conceptualization.

\section{A. Testimonial of Issue}

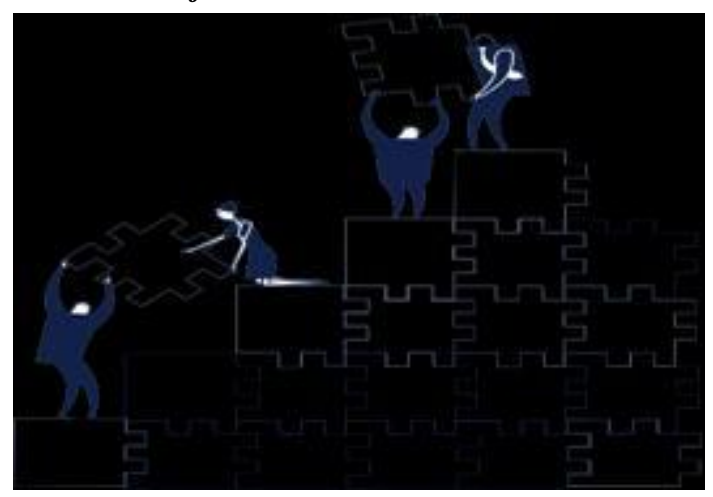

The Research in Organization citizenship behavior is very broad since its presentation about twenty years back (ST. Batermann, W.Dennis Organ). Organization citizenship behavior inquire about concentration in the impacts of Organization citizenship behavior on individual and Organization execution. There is an accord in the field of "Organization citizenship behavior" which is notable behavior in Organization ventures. Be that as it may, the precursors of Organization citizenship behavior are not well established. This Investigation centers around unmistakably characterizing the connection between Organization adequacy and organization citizenship behavior. The Investigation likewise examine ramifications of organization citizenship behavior \& attempts to discover in what ways it can advance organization citizenship behavior.

\section{B. Definition of Organization Citizenship Behavior}

Organization Citizenship Behavior: Organization citizenship behavior is a moderately fresh idea under execution investigation yet speaks to an extremely old human direct of deliberate activity and common guide with not at all solicitation aimed at compensation or prescribed recompenses consequently. Idea was initially presented during mid 1988 by Dennis Organ and hypothesis as well , it has been extended quickly during next centuries.

W.Dennis Organ \{1997\} recommended that Bormann and Motowidtlo's \{1993\} build under "relevant behavior" gave an increasingly valid meaning of organization citizenship behavior. Logical behaviors "try not to help the specialized center itself to such an extent as they bolster the more extensive Association, social, and mental condition in which the specialized center must capacity "). The definition isn't obfuscated by whichever thoughts of circumspection, prizes, or expectation of on-screen character. The definition just expect the behavior should bolster "the Organization, communal and mental condition" instead of the "specialized center." There is no particular thought process assumed in the on-screen character, nor another predecessors induced. The bias which exists that encompassing fluffy route amongst the specialized center. The vagueness would probably persevere.
As per Dennis W Organ \{1988\}, Definition of Organization citizenship behaviors is "Individual behavior that is discretionary, not directly or explicitly recognized by the prescribed reward system, and that in the aggregate promotes the effective functioning of the organization ". Dennis W Organ \{1988\} likewise noticed characterizing organization citizenship behavior as behavior which aren't officially compensated and excessively expansive, "in-job" behavior really ensure a prescribed reward.

\section{Dimensions of Organization Citizenship Behavior}

The reforming meaning of organization citizenship behavior implies that it is really hard to portray measurements or identify its origins. A wide range of qualities have been credited to the drivers and indicators of organization citizenship behavior. The exploration has been accumulated into 2 primary themes which are useful for examining or advancing citizenship practices.

(i) Kinds of behavior. Understanding the categories of comportment that fall under organization citizenship behavior (and that are forerunners to it) is a valuable method to recognize and empower them in workers. In their audit, Podaskkoff et.al. $\{2000\}$ consolidated the excess of 30 varieties of citizenship behavior established in the inscription they are as follows : (1) aid practices, (2) sporting , (3) authoritative reliability, (4) hierarchical consistence, (5) singular activity, (6) metro goodness, and (7) self-advancement.

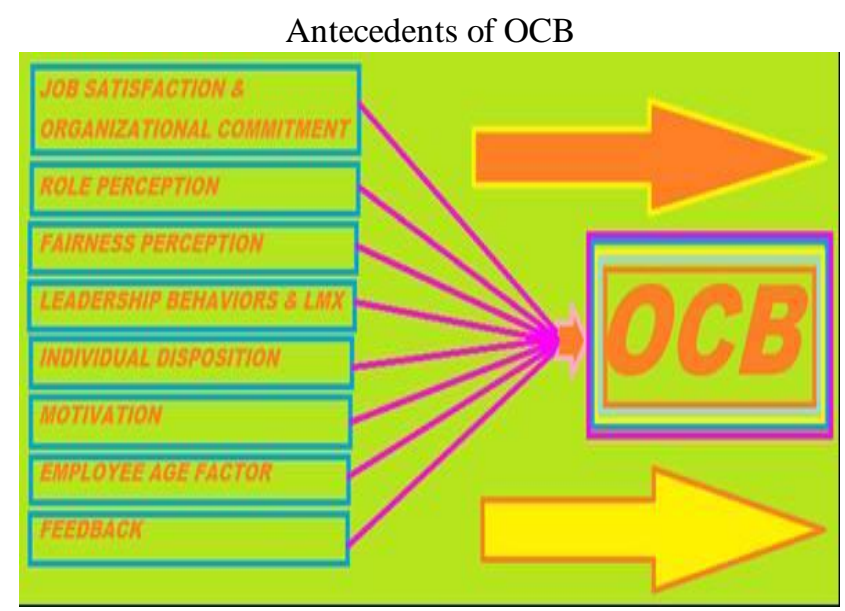

(ii) Heir of the organization citizenship behavior. Organization citizenship behavior that advantages people (organization citizenship behavior) and organization citizenship behavior that advantages the organization in general (organization citizenship behavior). organization citizenship behavior is identified with individual demeanors, \{for example\}, sympathy, while organization citizenship behavior is recognized with graded background. Hence, chief meaning to endow rehearses that benefits the organization, it needs to contemplate about what configurations encourages them, while conscription strategies may contemplate qualities identified with distinct organization citizenship behaviors. 


\section{Significance of the Investigation}

The Most important part in this investigation to develop and advance the Organization citizenship behavior. Organization Citizenship Conduct is significant in establishments. Organization citizenship is incredibly significant to establishments and add to execution and upper hand (Nemetth and Staws $\{1989\}$ ). The research is significant for all administrations whereas it need to make capability \& Organization viability. To advance organization citizenship behavior is most minimal expense, most ideal route for administrations to arrive at Organization adequacy.

\section{E. Significance of Organization Citizenship Behavior}

Effective administrations require representatives who would accomplish more than typical activity obligations \& give execution which is past desires. Organization citizenship behavior expose undertakings in which workers are happy to proceed beyond their acclaimed job prerequisites. Earlier proposition recommends and some examination bolsters the conviction that these behavior are corresponded with markers of Organization adequacy.

\section{Significance Of Organizational Citizenship Behavior}

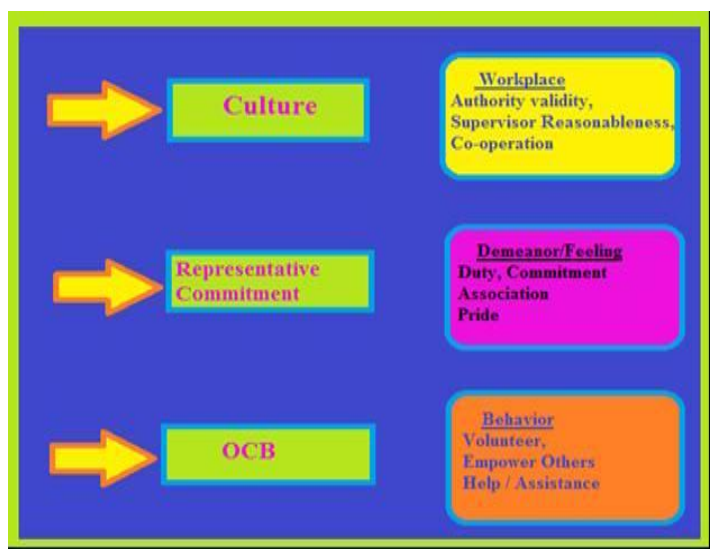

\section{F. Organization Citizenship Behavior Impact Operational Proficiency}

Dennis W Organ $\{1988\}$ distinguished 5 classifications of organization citizenship behavior : (a) self-sacrifice - the aiding of an individual colleague an errand, (b) affability alarming colleagues in the administration regarding variations which may impact their exertion, (c) uprightness completing a person's obligations past under base necessities, (d) Sporting - abstaining against griping under trifling issues, (e) community goodness - taking an interest in the administration of the organization

Table -1 : Behaviour in Organiosation

\begin{tabular}{|c|c|c|}
\hline $\begin{array}{l}\text { Organization } \\
\text { Citizenship } \\
\text { Behavior Style }\end{array}$ & Explanation & $\begin{array}{l}\text { Outcomes for } \\
\text { Organization }\end{array}$ \\
\hline Sportsmanship & $\begin{array}{l}\text { Willingness to hold back } \\
\text { minor burdens without } \\
\text { claim or protest }\end{array}$ & $\begin{array}{lr}\text { Fewer } & \text { minor } \\
\text { grumblings } & \text { enables } \\
\text { directors } & \text { to } \\
\text { concentrate } & \text { on } \\
\text { significant } & \text { occupation } \\
\text { capacities } & \end{array}$ \\
\hline
\end{tabular}

Employees give valuable proposals that may spare expenses

\begin{tabular}{|l|l|l|} 
Gentility & issues of governance & may spare expenses \\
\cline { 1 - 2 } $\begin{array}{l}\text { Summed } \\
\text { compliance }\end{array}$ & $\begin{array}{l}\text { Gestures inhibiting issues } \\
\text { for work partners }\end{array}$ & $\begin{array}{l}\text { Reduced requirement } \\
\text { for supervision, } \\
\text { training and } \\
\text { emergency board costs }\end{array}$ \\
\cline { 1 - 2 } Altruism & Summed up compliance & \\
\hline
\end{tabular}

Each element of organization citizenship behavior compromises substitute justification for the rapport. Selflessness, aiding colleagues creates the work structure increasingly profitable in context of the circumstance where one laborer shall utilize their leeway period to aid other in a progressively dire errand. Demos of community uprightness may integrate contribution schemes for cost advancement or further ability helping feelings, as it may legitimately impact yield

\section{Behavior in Organizations (Impacts)}

\begin{tabular}{|l|l|l|}
\hline OCB STYLE & Explanation & Results for Organization \\
\hline Sportsmanship & $\begin{array}{l}\text { Willingness to hold back } \\
\text { minor burdens mithout c him } \\
\text { or protest }\end{array}$ & $\begin{array}{l}\text { Ferr er minor grumblings } \\
\text { enables directors to } \\
\text { concentrate on signific ant } \\
\text { occupation capacities }\end{array}$ \\
Ciric Virtue & $\begin{array}{l}\text { Constructire inclusion in } \\
\text { issues of gorernance }\end{array}$ & $\begin{array}{l}\text { Employees gire raluable } \\
\text { proposals that may spare } \\
\text { expenses }\end{array}$ \\
\hline Gentility & $\begin{array}{l}\text { Gestures inhibiting issues for } \\
\text { nork partners }\end{array}$ & $\begin{array}{l}\text { Reduced requirement for } \\
\text { superrision, training and } \\
\text { emergency board costs }\end{array}$ \\
\hline Summed up compliance & More generic reliability & \\
\hline Altruism & Summed up compliance & \\
\hline
\end{tabular}

\section{G. Job Fulfillment}

Smitth. $\{1983\}$, Batemann $\{1978\}$ and W.Dennis Organ $\{1983\}$ directed main exploration in the forerunners of Organization Citizenship Conduct, securing position fulfillment acts as a best indicator. Following Seventeen years of exploration, work fulfillment is yet the main indicator of organization citizenship behavior. This is dangerous on the grounds that, unmistakably, work fulfillment is all by itself a difficult result looked for by Organization managers.

The subsequent ramifications are limited to get the job done that organization citizenship behavior is likely when laborers are fulfilled. There are similarly the same number of inquiries with respect to the precursors of occupation fulfillment as there are inquiries concerning the forerunners Organization citizenship behavior. Yet, agreeing to Penner, Middili and Kegelmeyers, (1997) the activity fulfillment isn't just one explanation behind the precise forecast of organization citizenship behavior

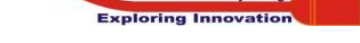




\section{H. Motivation}

Inspiration is another perception for downplaying organization citizenship behavior. Three thought process standards are frequently looked into. Survey organization citizenship behavior from these three thought process ideal models, one can all the more effectively represent the different methodologies taken in earlier organization citizenship behavior explore. The philanthropic way is secured very well with the connection thought process and portion of accomplishment intention, however the gloomier sideways is all the plainly comprehended from authority rationale. The intention is anything but difficult to perceive any reason why organization citizenship behavior may associate with evaluations of execution and why (A.H.Maslow; Harper \& Row, 1954).

This rationale based view additionally enables understand the different discoveries of research looking for character connects of organization citizenship behavior \{W.Dennis Organ, 1994\} . An extensive assortment of character qualities had been inspected in exploration yet the outcomes remains frustrating, since the main predictable connection rising is amongst the "enormous 5" attribute of good faith \& organization citizenship behavior measurement in a similar title. In fact the review organization citizenship behavior brought almost by various intentions, a person could perceive that distinctive character attributes can foresee organization citizenship behavior relying upon resident's thought process.

It is conceivable, in any case, that there are backhanded results of organization citizenship behavior that are identified with the workers' thought processes. For instance, if organization citizenship behavior are shown as supremacy thought processes, managers shall fortify behavior against outward recompenses, advancements, progressively obvious assignments. Directors might be unaware of such thought processes, seeing just the noticeable behavior. Colleagues, then again, may see the behavior from an alternate, increasingly political perspective. As the power-arranged resident additions support for such behavior from above, different workers can end up disheartened and separated, not having any desire to "play legislative issues" to excel. The subsequent result might be a culture of doubt, tattle, grievances, or unpretentious clash, dissolving attachment and group working in the unit.

At long last, the connection arranged native shall implement organization citizenship behavior to an extent, whereas the worker manager bond winds up useless. Like the idea of codependence in close to home connections, the broken rapport shall create more mischief compared with anything in the workplace. Intention centered in speculations of behavior experience the ill effects of absence of research philosophies that can legitimately quantify the builds

Maslow Hierarchical Theory Needs

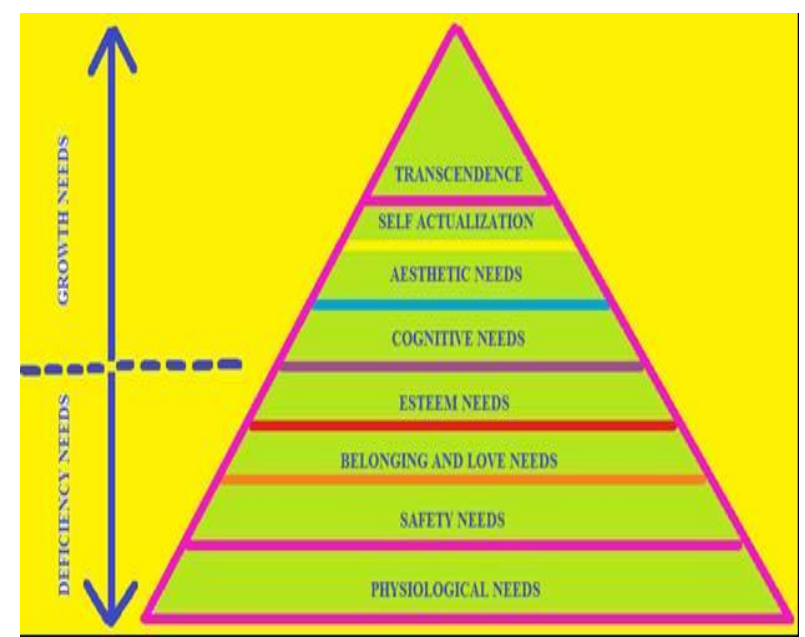

That is, rather than getting some information about their very own thought processes, look for the feelings and view of associates with regards to the intentions of the objective individual. Such an exploration procedure may likewise start to uncover the aberrant impacts of thought process centered organization citizenship behavior.

\section{SUMMARY}

With regard to assessment cited overhead, Network has a affirmative rapport in accordance to following Organization citizenship behavior. Partialities to conviction has a optimistic bond against coming about various leveled citizenship.

Organization based certainty as a center individual inciting progressive citizenship. Individual qualification would altogether be able to affect Organization citizenship. Extraordinary position that atmosphere can successfully influence progressive citizenship lead. Personalities with extraordinary collaboration \& affinity to reliance will undoubtedly acknowledge they can be a regarded bit of the relationship, to regard this activity, and because of this conviction, participate in conduct to have any sort of impact in the affiliation.

\section{CONCLUSIONS}

Organization and laborers who would do these things which is not a piece of normal arrangement of duties. Additionally, the substantiation shows that these affiliations have such agents beat. Along these lines, human subject assessments are stressed over Organization citizenship lead as a penniless variable.

Organization citizenship conduct have been normally abstracted as naturally and socially appealing code of conduct. It is the inspiration driving this article to stripe away inclinations and ascriptions for communal alluring quality and examine the conduct in their cautiously discernible structure. Accordingly, various perspectives broke down as a prospective reason that why agents may show organization citizenship behavior.

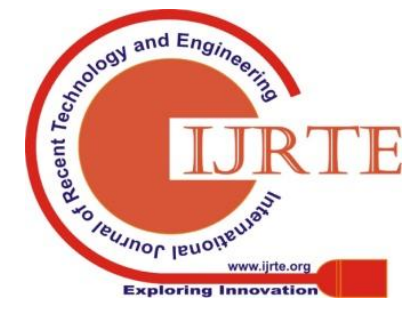




\section{An Examination to Advance / Develop Organization Citizenship Behavior}

Attainment, union, and supremacy is not new contemplations , anyway use of these aims to the examination of organization citizenship behavior gives another point of convergence to see organization citizenship behavior. More research is so far expected to endorse the contemplations imparted in this article.

As described by Dennis W Organ $\{1988\}$, organization citizenship behavior mirrors an "average warrior issue" which is so fundamental for the flourishing and extraordinary working of every affiliation. It means making an unrivaled appearing, attempting great past prescribed essentials, and filling the gap among frameworks and rules from one perspective, and vibrant realism on the another. organization citizenship behavior is ordinarily observed for applying amazingly incredible conduct for the affiliation and coolly supporting its people. As of not long ago, and to the degree we used to find, none of the assessment has scrutinized criticalness and repercussions of organization citizenship behavior conduct in third area. Plainly, the conduct is basic for reserved relationship since it impact their forcefulness \& profit. It must be centered around extending organization citizenship behavior among the paid agents. Along these lines, organization citizenship behavior address a historic segment of totally opportunity lead, most pertinent in third-division affiliations, which highlight estimations of persistent individual exercises especially among paid specialists. Along these lines it is interesting to take a gander at how organization citizenship behavior is appeared in social organizations inside work units of the disadvantage portion.

Organization citizenship is optional lead which isn't a bit of a delegate's prescribed business essentials, anyway that everything considered advances the convincing working of the affiliation. (Robbins, 1996). Successful affiliations need laborers who will achieve more than their commonplace action commitments and give execution that is past wants. Basically, in order to touch base at that objective, fill full agents work fulfillment, make appropriate work atmospheres are most noteworthy thing in the board authenticity.

\section{REFERENCES}

1. JM.Wernerr, , HRM review, 2000, Volume. 10, No.1, page no. 1-22

2. MP Podsakkoff, BS.Mc Kenzie, J.Bethh Painne, G.D. Bachrachh, Journal of management, 2000, Volume. 26. No. 3 page no. 513-563.

3. Walz, SM. \& Niehoff, BP, AM conference, pp. page no. 307-31, 1996

4. Sunil Kumar Singh June, 2007 ; Volume 19, Number 2 Articles.

5. W.Dennis Organ, Philips M.Podsakkoff \& Sco ; " Organization Citizenship Behavior: Its Nature, Backgrounds, and Significances"

6. Organ, D.W. organization citizenship behavior : Lexington, MA, 1988.

7. Organ. D.W. " The motivation base of Organization citizenship behavior. “ Research under Organization Behavior 1990" .

8. Staww \& LL Cumings, Research under Organization behavior Volume. 12 (pp. page no. 43-72).1993.

9. ST. Batermann, W.Dennis Organ , Job fulfillment and good soldier, AMJ, 1983, Volume. 26, No. 4, page no. 587-595

10. A.H.Maslow (Maslow Hierarchical Theory) ," A Motivations and Temperament" Harper and Row 1954.

\section{AUTHOR PROFILE}

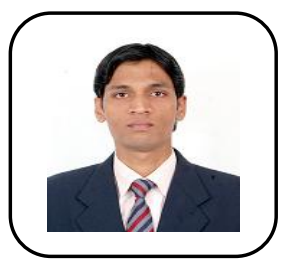

Mr.J.M.Jaffar Sadiq Assistant Professor, The New College (Autonomous), chennai, has a eminent track record of successful teaching, research and education reform, and has been teaching young, dynamic college students, I grew up in a family of labor to be honest, which inspired me to work hard at childhood stage itself and explore things in an exemplary manner and had a camaraderie with all the people whom i used to see and mingle. At the age of 15 i have passed my Matriculation board Examination and could not continue my studies further hence I gave my HSC examination privately and secured $83 \%$ successfully. Thereafter I got into Merit based seat at an esteemed Institution " The New College (Autonomous) " where I did my B.com in 2006, M.com in 2008 , M.phil (Commerce) in 2009 at "The Presidency College (Autonomous) ", M.B.A at MKU and pursuing Ph.D at St.Ann's College of Arts \& Science (Co-ed).. 